\title{
Development of a solar radiation sensor system with pyranometer
}

\author{
Muchamad Rizqy Nugraha, Andi Adriansyah \\ Department of Electrical Engineering, Universitas Mercu Buana, Jakarta, Indonesia
}

\begin{abstract}
Article Info
Article history:

Received Jan 20, 2021

Revised Nov 17, 2021

Accepted Nov 27, 2021

\section{Keywords:}

Pyranometer

Sensor system

Solar radiation

ABSTRACT

Solar energy is a result of the nuclear fusion process in the form of a series of thermonuclear events that occur in the Sun's core. Solar radiation has a significant impact on the lives of all living things on earth. The uses, as mentioned earlier, are when the solar radiation received requires a certain amount and vice versa. As a result, a more accurate instrument of solar radiation is required. A specific instrument is typically used to measure solar radiation parameters. There are four solar radiation parameters: diffusion radiation, global radiation, direct radiation, and solar radiation duration. Thus, it needs to use many devices to measure radiation data. The paper designs to measure all four-radiation data by pyranometer with particular modification and shading device. This design results have a high correlation with a global standard with a value of $\mathrm{R}=0.73$, diffusion with a value of $\mathrm{R}=0.60$ and a sufficiently strong direct correlation with a value of $\mathrm{R}=0.56$. It can be said that the system is much simpler, making it easier to monitor and $\log$ the various solar radiation parameters.
\end{abstract}

This is an open access article under the CC BY-SA license.

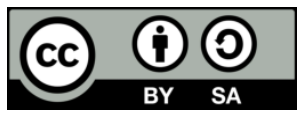

Corresponding Author:

Andi Adriansyah

Department of Electrical Engineering, Universitas Mercu Buana

Meruya Selatan Street, Kembangan, Jakarta 11650, Indonesia

Email: andi@mercubuana.ac.id

\section{INTRODUCTION}

Solar energy is a result of the nuclear fusion process in the form of a series of thermonuclear events that occur in the sun's core [1]. Solar radiation is responsible for this process. Solar radiation is critical to the survival of all alive things on earth. Numerous applications for solar radiation are available, ranging from providing solar water heating and solar pumping to solar drying of agricultural and animal products. In the future, it will be used as a health supplement for the health and liveliness of human [2], [3]. The applications mentioned above are when the received sun energy meets a certain value. If the radiation vale exceeds the required quantity, there will be sufferers, harm, and even tragedies. Several precise instruments of solar radiation are thus needed [4], [5].

For many years, many stations around the world have measured solar radiation [6]-[8]. The primary goal of these measurements was weather forecasting, agriculture, the prediction of travel plans, and the project of heating [9]-[11]. The data available primarily concern solar irradiance on the plane surface [12]-[14]. Several types of radiation are available, including direct radiation, diffusion radiation, global radiation, and solar radiation duration [13]-[16]. There are three powerful solar measuring instruments: pyrheliometers, pyranometers, and photoelectric sunshine recorders [17]-[19]. Unfortunately, it necessitates that all devices receive all of the necessary radiation instrumentation data [20]-[23]. A unique approach is required to get the required data with a minimal device [24]-[29]. 
As a result, this paper aims to create an integrated system for measuring solar radiation parameters to continue previous research [30]. The system can measure the four parameters needed with one sensor, namely the pyranometer sensor. The monitoring and data logging system will also be used as a web system to track measurement results on a personal computer (PC) or smartphone more efficiently. Measurement performance will be improved by combining a shading device system and a solar system that will operate according to location coordinates.

\section{MATERIALS AND METHOD}

\subsection{Measurements solar of radiation}

The sun radiates and the earth intercepts a fraction of the energy flow categorized by the solar constant. The solar constant is essentially a measurement of the solar flux density per unit time, perpendicular to the radiation direction. There is also a small variation in the solar constant due to variations in the brightness of the sun. This condition includes all types of radiation, a significant segment of which is lost when light enters through the atmosphere.

In general, it can be said that the direct radiation reaching the earth's surface is never more than $83 \%$ of the original solar energy flow. Radiation originating directly from the solar disk is defined as direct radiation (E). While the radiation that is scattered and reflected then leads to the earth's surface from all directions, defined the accumulation of direct radiation and diffusion radiation is defined as global radiation (Eg). This correlation is shown in (1) [31]-[33].

$$
E g \downarrow=E \cos \alpha+E d \downarrow
$$

Where, $\alpha$ there is a zenith angle, the angle among the incident radius and the normal to the horizontal instrument flat.

The quantity of solar radiation on earth's surface can be measured instrumentally, and accurate devices are important for providing background solar data for solar energy conversion implementations. Pyrheliometer, pyranometer and photoelectric sunshine recorders are three major kinds of devices used to measure solar radiation. The three parameters of solar radiation can be measured quantitatively using available instruments. The accuracy, optimization and efficiency measurement of these parameters becomes very significant. Various implementations of solar energy rely on the results of these instruments. The three types of sensors commonly used are pyrheliometer, pyranometer, and photoelectric sunlight recorder.

\subsection{System design}

In general, the designed system consists of four parts, as shown in Figure 1. The first part of the system is the input section. The main component of this section includes the pyranometer sensor. The sensor is integrated with time using a time server from the Indonesian meteorological climatology and geophysics agency (BMKG) at http://ntp.bmkg.go.id to get real and precise time. In addition, a shading device is used to optimize the radiation calculation parameters generated.

The second part of the system is a microcontroller unit. This section is to process the incoming data, perform calculations from several necessary processes, and produce output in the form of actuators that move a motor and calculate some results according to the applicable algorithm. The microcontroller used is the espressif systems (ESP32), a low-priced and energy-efficient microcontroller with integrated Wi-Fi and dualmode Bluetooth. The ESP32 microcontroller uses the Tensilica Xtensa LX6 microprocessor as the core.

While the third part of the system consists of a motor and a data logger. According to the elevation angle, the motor works to drive the system, azimuth angle and sun position data. The process of calculating radiation parameters corresponds to the position of the sun in real-time. The data logger feature will save the calculation results of radiation parameters also in real-time, as well. Then, a web-based display system displays all the calculation results in the form of several solar radiation parameters on a PC or smartphone [34], [35].

The system is designed to work to get 4 (four) parameters of solar radiation using one pyranometer sensor as follows: First, the pyranometer sensor works to get the global radiation (Eg) or G value. After that, the shading unit device is driven by a servo motor gradually at a certain angle. The movement of the shading device is carried out to obtain the solar radiation parameters that are blocked by it. Figure 2 illustrates the movement of shading devices based on time. The system obtains the radiation diffusion value (Ed) or D in this position. The direct radiation (E) or L value is calculated using (1), where the system has obtained previously global and diffusion radiation values. The calculation of the value of direct radiation in this system ignores the elevation angle value of the sun so that calculation (2) is obtained. 


$$
L=G-D
$$

After getting the value of direct radiation $(E)$ or $L$ is obtained by (2). Next, the system will measure the duration of solar radiation. The duration of solar radiation is sun exposure when the radiation value is more than $120 \mathrm{Watt} / \mathrm{m}^{2}$ [36]. Based on this, the system will increase the time by 5 minutes (which is the system time from global radiation measurement to direct radiation) if direct radiation has a value of more than $120 \mathrm{Watt} / \mathrm{m}^{2}$. Otherwise, there is no additional time. Finally, all of the values are saved in a data logger and transmitted to the monitoring station via internet transmission. Officers can obtain the value generated using a PC or smartphone.

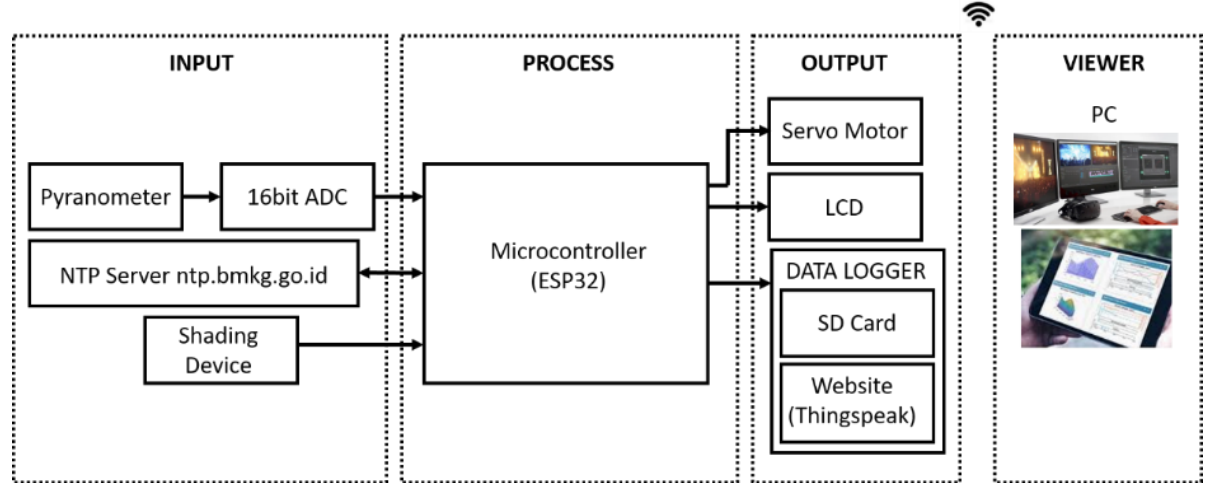

Figure 1. Block diagram of the system

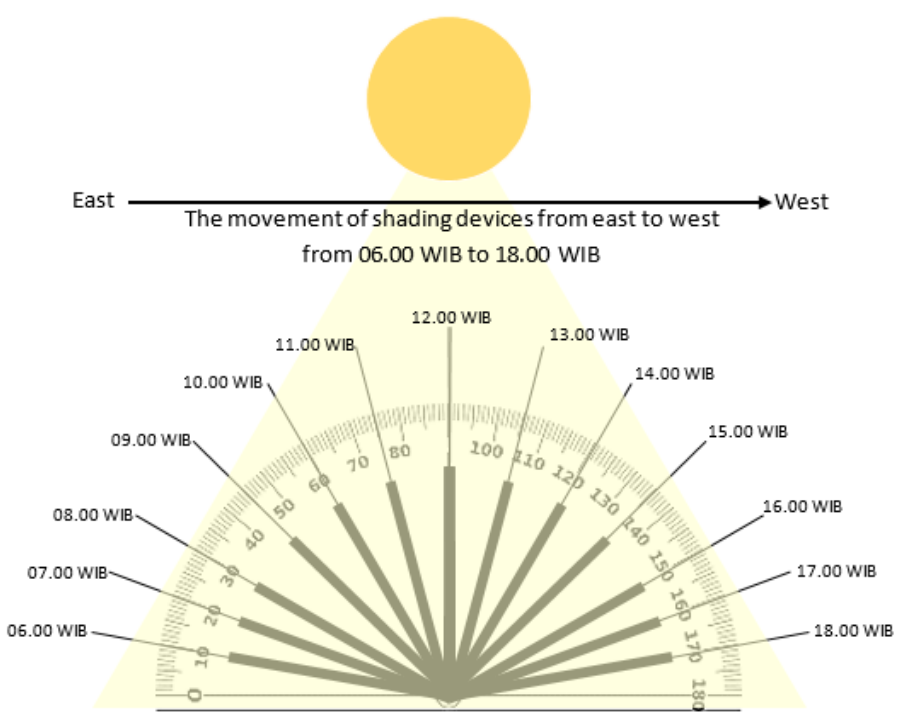

Figure 2. An illustration of the movement of shading devices based on time

The automatic solar radiation system (ASRS) was used to carry out the solar radiation reading to provide benchmark data. The data from the developed sensor model will be compared with the benchmark data to evaluate the proposed model's performance. Testing was carried out from Oct 30, 2020, to Nov 4, 2020. We assessed the test equipment's performance by comparing the test equipment with standard equipment, then analyzed using simple linear regression to determine how strong the test equipment data's correlation with standard equipment data. The analysis is also performed by calculating the mean absolute percent error (MAPE). The MAPE is a statistical calculation to measure the test equipment's data accuracy as a percentage of the error. The data accuracy of the test equipment is better if the MAPE value is getting smaller. The MAPE value is calculated as in (3) and be interpreted into several types as listed in Table 1. 


$$
M A P E=\frac{1}{n} \sum_{t=1}^{n} \frac{|\hat{y} t-y t|}{y t} \times 100
$$

Table 1. Interpretation of typical MAPE values

\begin{tabular}{cc}
\hline MAPE Value & Interpretation \\
\hline$<10 \%$ & Very Good \\
$10-20 \%$ & Good \\
$20-50 \%$ & Pretty Good \\
$>50 \%$ & Bad \\
\hline
\end{tabular}

\section{RESULTS AND DISCUSSION}

Figures 3 and 4 compare global radiation measurements for test equipment and standard equipment. There is a correlation value of $\mathrm{R} 2=0.53$ for the data generated by the two global radiation measurements, so $\mathrm{R}=0.73$. The 0.73 correlation value means that there is a strong correlation between the two variables. There is an error value in the system that has been made where this value is $61.8 \mathrm{Wat} / \mathrm{m}^{2}$ in global radiation. The MAPE method was used to analyze data from the test results of the test equipment. The MAPE value of the global radiation measurement for the test equipment from the calculation results is $40.18 \%$, meaning that the test equipment has adequate criteria for measuring global radiation.

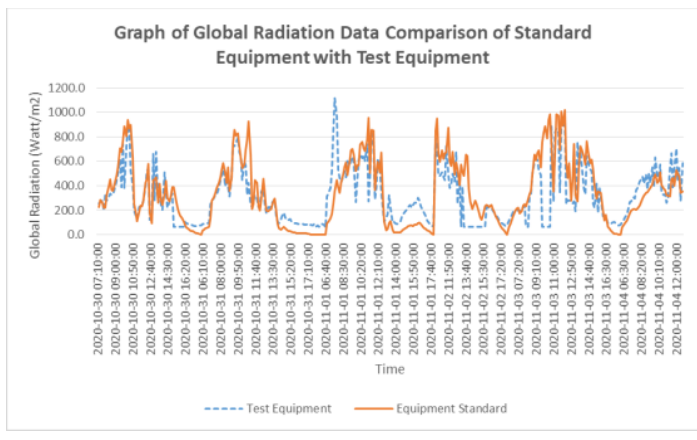

Figure 3. Global radiation data comparison of standard equipment with test equipment

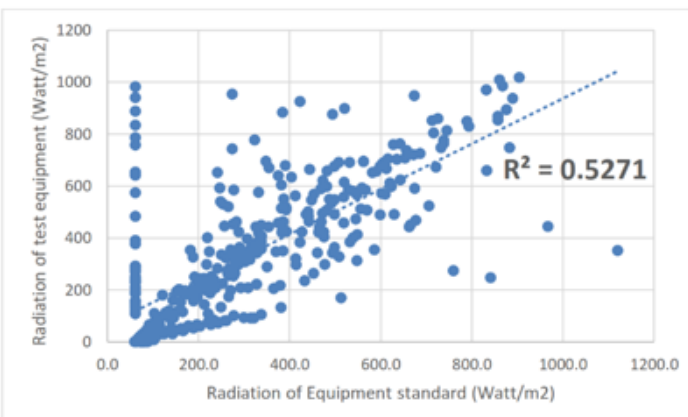

Figure 4. Scatter plot of the global radiation data comparison of standard equipment with test equipment

Figures 5 and 6 show a data comparison of diffusion radiation measurements for test equipment and standard equipment. The data generated by the two diffusion radiation measurements have a correlation value of $\mathrm{R} 2=0.36$ so that $\mathrm{R}=0.60$. The correlation value of 0.60 means that the two variables have a strong correlation. There is an error value in the system that has been made, where this value is $129.83 \mathrm{Watt} / \mathrm{m}^{2} \mathrm{in}$ diffusion radiation. The data from the test results of the test equipment were analyzed using the MAPE method. From the calculation results, the diffusion radiation measurement's MAPE value is $49.31 \%$, which means that the test equipment has the right enough criteria for measuring diffusion radiation.

A data comparison of direct radiation measurements for test equipment and standard equipment is shown in Figures 7 and 8 . There is a correlation value of $R 2=0.31$ for the data generated by the two direct radiation measurements, so $\mathrm{R}=0.56$. The 0.56 correlation value means that there is a strong enough correlation between the two variables. An error value is generated in the system, where this value in direct radiation is $129.83 \mathrm{Watt} / \mathrm{m}^{2}$. The MAPE method was used to analyze data from the test results of the test equipment. The MAPE value of the direct radiation measurement for the test equipment from the calculation results is $108.10 \%$, which means that the test equipment has insufficient direct radiation measurement criteria.

Table 2 listed a comparison of the sunshine duration data between the standard equipment and the test equipment. It is found that the duration of the sun's exposure to the standard equipment and the test equipment has a difference in the average duration of solar radiation, which is 48 minutes. The data from the test results of the test equipment were analyzed using the MAPE method. From the calculation results, the MAPE value of the sunshine duration measurement for the test equipment is $10.17 \%$, which means that the test equipment has the proper criteria for measuring sunshine duration. 


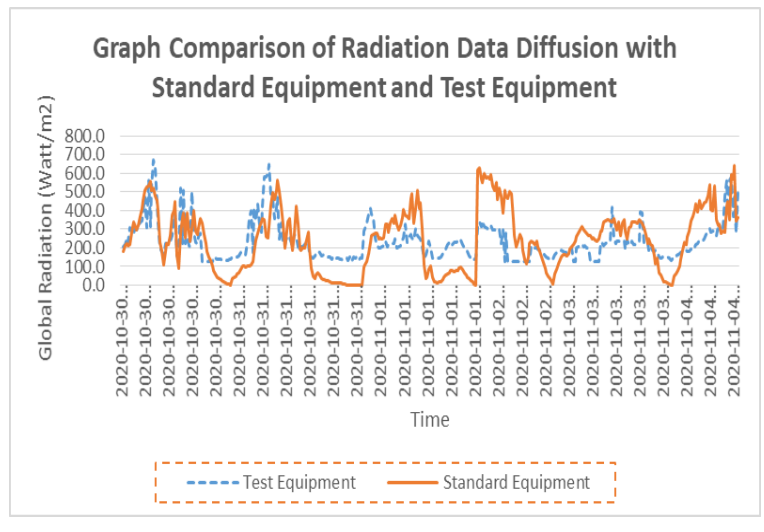

Figure 5. Diffusion radiation data comparison of standard equipment with test equipment

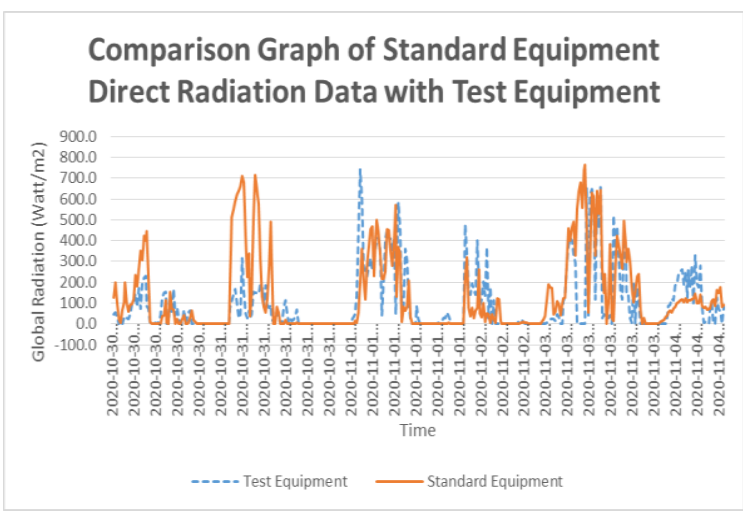

Figure 7. Direct radiation data comparison of standard equipment with test equipment

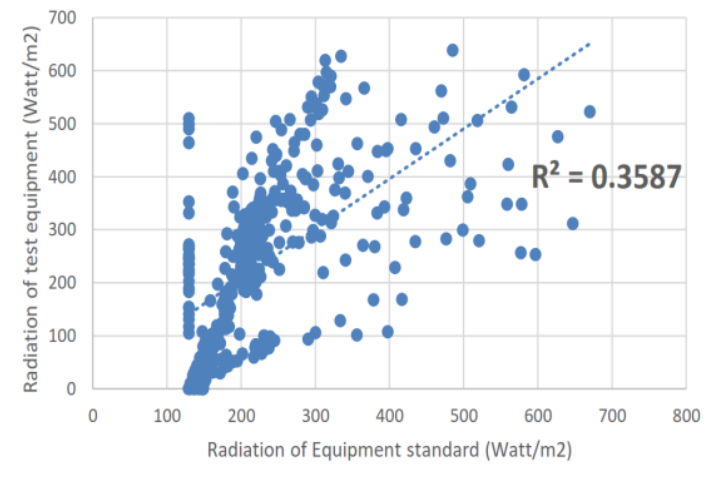

Figure 6. Scatter plot of the diffusion radiation data comparison of standard equipment with test equipment

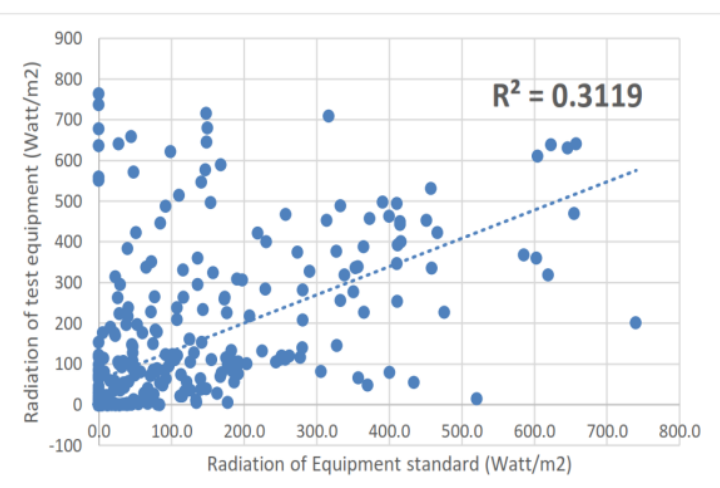

Figure 8. Scatter plot of the direct radiation data comparison of standard equipment with test equipment

Table 2. Comparison of sunshine duration data

\begin{tabular}{cccccc}
\hline No & Date & Time (UTC+7) & $\begin{array}{c}\text { Sunshine duration of } \\
\text { equipment standard } \\
\text { (minutes) }\end{array}$ & $\begin{array}{c}\text { Sunshine duration of test } \\
\text { equipment } \\
\text { (minutes) }\end{array}$ & $\begin{array}{c}\text { Difference } \\
\text { (minutes) }\end{array}$ \\
\hline 1 & $30 / 10 / 2020$ & $07.10-17.50$ & 123 & 100 & 23 \\
2 & $31 / 10 / 2020$ & $06.00-18.50$ & 215 & 110 & 105 \\
3 & $1 / 11 / 2020$ & $06.40-17.50$ & 246 & 270 & -24 \\
4 & $2 / 11 / 2020$ & $10.20-17.50$ & 100 & 250 & -30 \\
5 & $3 / 11 / 2020$ & $06.10-17.50$ & 401 & 170 & 151 \\
6 & $4 / 11 / 2020$ & $06.10-12.30$ & 232 & & 62 \\
& \multicolumn{7}{c}{ The average difference (minutes) } \\
\hline
\end{tabular}

\section{CONCLUSION}

Four solar radiation parameters have been measured and recorded by this system: global radiation, diffusion radiation, direct radiation, and duration of solar radiation. The developed model strongly correlates with the standard measurement tool ASRS in terms of global radiation, diffusion radiation and direct radiation levels, and a monitor for direct radiation levels with a value of $\mathrm{R}=0.56$. The MAPE score is based on good criteria for the sunshine duration with a MAPE value of $10.17 \%$, good criteria for global radiation measurement with a MAPE value of $40.18 \%$, good criteria for diffusion radiation measurement with a MAPE value of $49.31 \%$, and bad criteria for direct radiation measurement with a MAPE value of $108.10 \%$. All of the parameters can be measured precisely using the system. It is much easier to monitor and record the various solar radiation parameters now that information is transmitted via the internet. 


\section{ACKNOWLEDGEMENTS}

The authors would like to express their gratitude to the Directorate General of Higher Education, Ministry of Education and Culture of the Republic of Indonesia, for financial support in the Master's Research Scheme No. B/87/E3/A.00/2020. Many thanks to the Universitas Mercu Buana Research Centre for their assistance and encouragement.

\section{REFERENCES}

[1] Y. Zhang, J. Ren, Y. Pu, and P. Wang, "Solar energy potential assessment: A framework to integrate geographic, technological, and economic indices for a potential analysis," Renewable Energy, vol. 149, pp. 577-586, Apr. 2020, doi: 10.1016/j.renene.2019.12.071.

[2] H. Fang, J. Li, and W. Song, "Sustainable site selection for photovoltaic power plant: An integrated approach based on prospect theory," Energy Conversion and Management, vol. 174, pp. 755-768, Oct. 2018, doi: 10.1016/j.enconman.2018.08.092.

[3] International Energy Agency (IEA), Technology roadmap: Solar photovoltaic energy. UK: OECD Publishing, 2010.

[4] Y. Wu, B. Zhang, C. Wu, T. Zhang, and F. Liu, "Optimal site selection for parabolic trough concentrating solar power plant using extended PROMETHEE method: A case in China," Renewable Energy, vol. 143, pp. 1910-1927, Dec. 2019, doi: 10.1016/j.renene.2019.05.131.

[5] M. M. Caldwell et al., "Effects of increased solar ultraviolet radiation on terrestrial ecosystems," Journal of Photochemistry and Photobiology B: Biology, vol. 46, no. 1-3, pp. 40-52, Oct. 1998, doi: 10.1016/S1011-1344(98)00184-5.

[6] X. Zhang et al., "Solar radiation allocation and spatial distribution in Chinese solar greenhouses: Model development and application," Energies, vol. 13, no. 5, Art. no. 1108, Mar. 2020, doi: 10.3390/en13051108.

[7] M. Mussard, "Solar energy under cold climatic conditions: A review," Renewable and Sustainable Energy Reviews, vol. 74, pp. 733-745, Jul. 2017, doi: 10.1016/j.rser.2017.03.009.

[8] H. Eteruddin, A. Atmam, D. Setiawan, and Y. Z. Arief, "Effects of the temperature on the output voltage of mono-crystalline and poly-crystalline solar panels," Sinergi, vol. 24, no. 1, Art. no. 73, Dec. 2019, doi: 10.22441/sinergi.2020.1.010.

[9] F. Berroug, E. K. Lakhal, M. El Omari, M. Faraji, and H. El Qarnia, "Thermal performance of a greenhouse with a phase change material north wall," Energy and Buildings, vol. 43, no. 11, pp. 3027-3035, Nov. 2011, doi: 10.1016/j.enbuild.2011.07.020.

[10] F. Meza and E. Varas, "Estimation of mean monthly solar global radiation as a function of temperature," Agricultural and Forest Meteorology, vol. 100, no. 2-3, pp. 231-241, Feb. 2000, doi: 10.1016/S0168-1923(99)00090-8.

[11] M. Abdunnabi, B. Belgasim, M. BenAbead, and F. Mohamed, "Performance analysis of solar heat generation system for multipurpose applications," in 2020 11th International Renewable Energy Congress (IREC), Oct. 2020, pp. 1-5, doi: 10.1109/IREC48820.2020.9310438.

[12] A. A. N. G. Sapteka, A. A. N. M. Narottama, K. A. Yasa, P. Jariyatantiwait, and I. M. Sajayasa, "Modelling of monthly clear sky solar irradiation on horizontal surface in Denpasar City," in 2019 International Conference on Electrical, Electronics and Information Engineering (ICEEIE), Oct. 2019, pp. 7-10, doi: 10.1109/ICEEIE47180.2019.8981436.

[13] D. H. W. Li and S. Lou, "Review of solar irradiance and daylight illuminance modeling and sky classification," Renewable Energy, vol. 126, pp. 445-453, Oct. 2018, doi: 10.1016/j.renene.2018.03.063.

[14] X. Sun, J. M. Bright, C. A. Gueymard, B. Acord, P. Wang, and N. A. Engerer, "Worldwide performance assessment of 75 global clear-sky irradiance models using principal component analysis," Renewable and Sustainable Energy Reviews, vol. 111, pp. 550-570, Sep. 2019, doi: 10.1016/j.rser.2019.04.006.

[15] R. K. Swartman and O. Ogunlade, "Solar radiation estimates from common parameters," Solar Energy, vol. 11, no. 3-4, pp. 170-172, Jul. 1967, doi: 10.1016/0038-092X(67)90026-6

[16] M. Guermoui, F. Melgani, K. Gairaa, and M. L. Mekhalfi, "A comprehensive review of hybrid models for solar radiation forecasting," Journal of Cleaner Production, vol. 258, p. 120357, Jun. 2020, doi: 10.1016/j.jclepro.2020.120357.

[17] T. Pavlovic, "Solar energy: The sun and photovoltaic technologies," Green Energy and Technology (UK: Springer, Cham), 2020.

[18] F. Woldehanna, Photovoltaic system engineering. Addis Ababa; Addis Ababa University Press, 2020.

[19] H. A. L. Ouali, B. Raillani, S. El Hassani, M. A. Moussaoui, A. Mezrhab, and S. Amraqui, "Techno-economic evaluation of very large-scale photovoltaic power plant, case study: Eastern Morocco," in 2020 th International Conference on Renewable Energies for Developing Countries (REDEC), Jun. 2020, pp. 1-5, doi: 10.1109/REDEC49234.2020.9163890.

[20] L. W. Jun, M. S. Jadin, and N. Sulaiman, "Development of microcontroller based portable solar irradiance meter using mini solar cell," in Lecture Notes in Electrical Engineering, Springer Singapore, pp. 1125-1137, 2021.

[21] K. Kulesza, "Spatiotemporal variability and trends in global solar radiation over Poland based on satellite-derived data (19862015)," International Journal of Climatology, vol. 40, no. 15, pp. 6526-6543, Dec. 2020, doi: 10.1002/joc.6596.

[22] L. Cornejo-Bueno, C. Casanova-Mateo, J. Sanz-Justo, and S. Salcedo-Sanz, "Machine learning regressors for solar radiation estimation from satellite data," Solar Energy, vol. 183, pp. 768-775, May 2019, doi: 10.1016/j.solener.2019.03.079.

[23] A. A. Zakri, N. Nurhalim, D. P. H. Simanulang, and I. Tribowo, "Photovoltaic modeling methods based on matlab simulink implementation," Sinergi, vol. 22, no. 1, p. 1, Feb. 2018, doi: 10.22441/sinergi.2018.1.001.

[24] J. Cross, "Capturing crisis," The Cambridge Journal of Anthropology, vol. 38, no. 2, pp. 105-124, Sep. 2020, doi: 10.3167/cja.2020.380208.

[25] H. Melin, "Towards a solution to the energy crisis," Nature Astronomy, vol. 4, no. 9, pp. 837-838, Sep. 2020, doi: 10.1038/s41550-020-1167-3.

[26] U. Berardi and J. Graham, "Investigation of the impacts of microclimate on PV energy efficiency and outdoor thermal comfort," Sustainable Cities and Society, vol. 62, Art. no. 102402, Nov. 2020, doi: 10.1016/j.scs.2020.102402.

[27] B. Li, B. Shi, Z. Yao, M. Kumar Shukla, and T. Du, "Energy partitioning and microclimate of solar greenhouse under drip and furrow irrigation systems," Agricultural Water Management, vol. 234, Art. no. 106096, May 2020, doi: 10.1016/j.agwat.2020.106096.

[28] W. B. Stine and M. A. Geyer, Power from the sun. Washington: D.C: Library of Congress, 1986

[29] K. G. Ruddick et al., "A review of protocols for fiducial reference measurements of downwelling irradiance for the validation of satellite remote sensing data over water," Remote Sensing, vol. 11, no. 15, Art. no. 1742, Jul. 2019, doi: 10.3390/rs11151742.

[30] M. R. Nugraha and A. Adriansyah, "Optimization of sensor model for solar radiation measurement with a pyranometer," IOP Conference Series: Earth and Environmental Science, vol. 739, no. 1, Art. no. 012080, Apr. 2021, doi: 10.1088/17551315/739/1/012080. 
[31] H. Jiang, Y. Yang, Y. Bai, and H. Wang, "Evaluation of the total, direct, and diffuse solar radiations from the ERA5 reanalysis data in China," IEEE Geoscience and Remote Sensing Letters, vol. 17, no. 1, pp. 47-51, Jan. 2020, doi: 10.1109/LGRS.2019.2916410.

[32] V.-E. Toader, P. F. Biagi, I.-A. Moldovan, A. Marmureanu, and A. Mihai, "Evaluation of the solar radiation in a seismic zone," IOP Conference Series: Earth and Environmental Science, vol. 362, Art. no. 012069, Nov. 2019, doi: 10.1088/1755$1315 / 362 / 1 / 012069$.

[33] J. A. Duffie and W. A. Beckman, Solar engineering of thermal processes. Hoboken, NJ, USA: John Wiley and Sons, Inc., 2013.

[34] A. Adriansyah, A. W. Dani, and G. I. Nugraha, "Automation control and monitoring of public street lighting system based on internet of things," in 2017 International Conference on Electrical Engineering and Computer Science (ICECOS), Aug. 2017, pp. 231-236, doi: 10.1109/ICECOS.2017.8167140.

[35] A. Adriansyah, S. Budiyanto, J. Andika, A. Romadlan, and N. Nurdin, "Public street lighting control and monitoring system using the internet of things," in AIP Conference Proceedings 2217, 2020, Art. no. 030103, doi: 10.1063/5.0000594.

[36] Guide to meteorological instruments and methods of observation. Switzerland: WMO-No.8 eight Edition, 2014.

\section{BIOGRAPHIES OF AUTHORS}

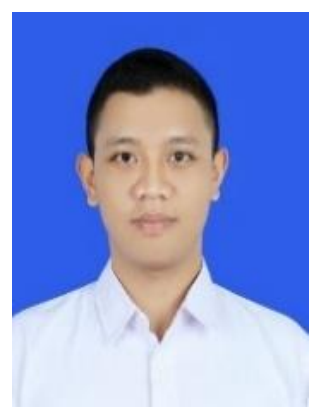

Muchamad Rizky Nugraha (D) SC SC P is a Bachelor Engineering at College of Meteorology Climatology and Geophysics, Tangerang, Indonesia. After that, he graduated from Post Graduate School of Electrical Engineering in Mercu Buana University. He became an engineer at Meteorology, Climatology and Geophysics Agency-Indonesia (BMKG), 2013-2017 at El Tari's Kupang Meteorological office. From 2017-now he works at College of Meteorology Climatology and Geophysics, Tangerang, Indonesia. He can be contacted at email: mrizqynugraha@gmail.com.

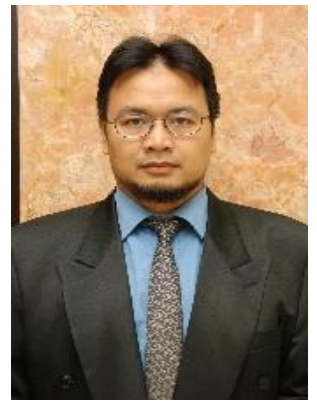

Andi Adriansyah (D) SC SC born in 1970, is a professor of Electrical Engineering at Universitas Mercu Buana. In 1994, he completed his undergraduate studies in Electrical Engineering at Universitas Indonesia in Indonesia. His master's and doctoral degrees were earned at Malaysia's Universiti Teknologi Malaysia in 1998 and 2007, respectively. He does research in mechatronics, robotics, control and automation, artificial intelligence, and the Internet of Things (IoT).He can be contacted at email: andi@mercubuana.ac.id. 